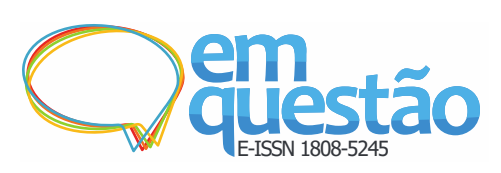

\title{
Diagnóstico do processo de implantação do INSS Digital: perspectivas da gestão da informação
}

\author{
Patrícia Soares da Silva Bertotti \\ Mestranda; Universidade Federal de Santa Catarina, Florianópolis, SC, Brasil; \\ patricia.bertotti@outlook.com \\ Ana Clara Cândido \\ Doutora; Universidade Federal de Santa Catarina, Florianópolis, SC, Brasil; \\ acc.anaclara@gmail.com \\ Luciane Paula Vital \\ Doutora; Universidade Federal de Santa Catarina, Florianópolis, SC, Brasil; \\ luciane.vital@ufsc.br
}

\begin{abstract}
Resumo: No poder executivo federal tramita considerável volume de documentos e o seu cuidado não deve ater-se à sua guarda; deve também envolver a sua preservação, garantindo o acesso a longo prazo. Este trabalho busca ressaltar, mediante uma pesquisa do atual cenário do processo de transformação digital no Instituto Nacional do Seguro Social (INSS), o desafio de produzir os documentos arquivísticos digitais e de mantê-los confiáveis, autênticos e acessíveis. Este estudo tem por objetivo identificar e apontar as perspectivas de gestão da informação no processo de transformação digital no Instituto Nacional do Seguro Social a partir de uma análise diagnóstica. Caracteriza-se como uma pesquisa qualitativa, de caráter exploratório e descritivo, utilizando como procedimento metodológico um estudo de caso aplicado. Os resultados obtidos expressam a necessidade de a instituição adotar uma política de gestão que contemple todos os aspectos da gestão da informação, desde a produção até a destinação final, já que seus documentos têm a necessidade de preservação a longo prazo.
\end{abstract}

Palavras-chave: Arquivologia. Gestão da informação. Preservação digital. Documento digital. 


\section{Introdução}

Ao longo dos anos as instituições, em seu processo contínuo e acelerado de mudanças no âmbito tecnológico, veem sua produção documental em crescimento constante e célere. Essa preocupação com a crescente produção documental, atualmente se dá tanto em arquivos analógicos quanto em arquivos digitais, sendo inúmeros os desafios que surgem com a falta de planejamento das organizações para gerir esses documentos, da qual resultam uma produção sem controle, armazenamentos inadequados e sem critérios.

Uma gestão de documentos eficaz possibilita a organização, o acesso e o compartilhamento de informações de uma instituição. Neste sentido a Lei 8.159/1991, que dispõe sobre a política nacional de arquivos públicos e privados e dá outras providências, apresenta como definição de gestão de documentos "O conjunto de procedimentos e operações técnicas referentes a sua produção, tramitação, uso, avaliação e arquivamento em fase corrente e intermediária, visando a sua eliminação ou recolhimento para guarda permanente.”.

O governo federal brasileiro, assim como o de outras nações, passa por um processo de transformação digital que tem por objetivo primeiro melhorar o atendimento ao cidadão. Essa melhora visa à transparência e ao controle social de seus serviços e ações, desburocratizando processos.

Nesse contexto se insere o Instituto Nacional do Seguro Social (INSS), instituição que busca por inovação nos seus processos de trabalho, mantendo o padrão de atendimento com uma quantidade menor de servidores e recursos, atendendo às demandas dos cidadãos, que se tornam frequentes diante do cenário informacional.

Esse novo fluxo de trabalho está sendo implantado por meio do projeto INSS Digital, que impôs uma nova e importante demanda: preservar digitalmente os documentos que servem de base para o reconhecimento dos direitos do cidadão contribuinte. Produzir os documentos arquivísticos digitais e mantê-los confiáveis, autênticos e acessíveis é um desafio para essa instituição.

Uma avaliação correta desses documentos se faz necessária. Ela deve estar embasada em normas e leis que amparem a guarda e o descarte adequado desses 
documentos, evitando assim perdas e descartes de documentos com valor legal, pois é na avaliação que ocorre todo o processo de análise e seleção dos documentos, que objetiva determinar os prazos de guarda e sua destinação final (INDOLFO, 2012).

Nesse contexto destaca-se o papel do arquivista, com conhecimento técnico para atuar na gestão arquivística de documentos e comprometido com a produção, preservação e difusão das informações, viabilizando a recuperação da informação de forma rápida e eficaz. A partir desta visão sobre o papel do arquivista e tendo-se em consideração o caso do INSS Digital como plano de fundo, serão tratadas as potencialidades da gestão da informação e da atuação arquivística enquanto suporte especializado, aproximando-se assim do campo da gestão de documentos.

Este estudo aborda e questiona como se dá a garantia de preservação a longo prazo e recuperação da informação dos documentos que servem de base para concessão de benefícios aos cidadãos e como está atualmente o processo de transformação digital no INSS.

Assim, o objetivo desta pesquisa consiste em identificar e apontar as perspectivas de gestão da informação no processo de transformação digital no INSS a partir de uma análise diagnóstica.

Justifica-se o tema pela necessidade de preservação das informações dos cidadãos, acumuladas no decorrer do seu tempo de contribuição, assim como pela necessidade de preservação da memória institucional da organização, baseada nos requerimentos de benefícios aos quais os cidadãos venham a ter direto.

Uma Arquivologia no contexto brasileiro comprometida com metodologias e técnicas já consolidadas de produção, uso, tramitação, preservação e guarda dos documentos poderá contribuir para a instituição com o desenvolvimento de uma gestão de documentos eficiente e capaz de promover uma preservação digital com a garantia de autenticidade dos seus documentos.

\section{Gestão da informação: uma síntese}

A informação assume hoje, para as instituições, um valor considerável nos processos de 


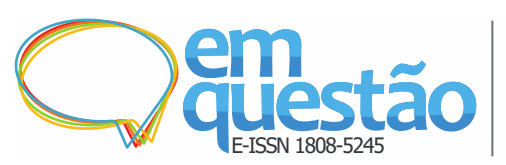

Diagnóstico do processo de implantação do INSS Digital: perspectivas e gestão da informação

Patrícia Soares Silva Bertotti, Ana Clara Cândido, Luciane Paula Vital

tomada de decisão, porém é tratada, na maioria das vezes, com negligência quando comparada a outras funcionalidades ou setores dessas instituições. O Dicionário brasileiro de terminologia arquivística define gestão da informação como a "Administração do uso e circulação da informação, com base na teoria ou ciência da informação.” (BRASIL, 2005, p. 100).

Para um melhor entendimento da importância da "informação", alguns conceitos são pertinentes. Para Le Coadic (2004), a informação pode ser apresentada de forma escrita, oral ou audiovisual, mas necessita de um suporte.

Em síntese, "Dados são um conjunto de fatos distintos e objetivos, relativos a eventos.". Devemos conceber a informação "Como dados que fazem a diferença." e devemos pensar que "O conhecimento se produz em mentes que trabalham." (DAVENPORT; PRUSAK, 2003, p. 2-6).

Davenport (1998, p. 91), menciona que "O uso efetivo da informação, muito mais do que qualquer tecnologia, pode alterar os rumos da organização.”. Nesse sentido, uma política de informação definida vai permitir à instituição alcançar seus objetivos de maneira eficaz, e, concomitantemente ao planejamento estratégico, torna-se um instrumento relevante na identificação das necessidades de informação da instituição (DAVENPORT, 1998).

O autor ainda explica que "[...] o gerenciamento da informação pode ser utilizado tanto para distribuir o poder como para centralizá-lo.” (DAVENPORT, 1998, p. 91) e aponta quatro tipos de políticas de informação: 1) Utopia tecnocrática: foca na abordagem técnica, a tecnologia como solução absoluta; 2) Anárquico: não existe gerenciamento da informação, cada um gerencia sua informação; 3) Monárquico: o líder é quem decide como fazer o gerenciamento da informação; 4) Feudalista: muito poucas decisões são centralizadas, o gerenciamento da informação é feito com a participação de todos na instituição.

Cada instituição precisa se adequar e se identificar nesse contexto, distinguir qual política está predominando, avaliar se a política que está predominando é a mais 
apropriada e aprimorar o que for necessário nesse processo de gerenciamento da informação (DAVENPORT, 1998).

Em busca de lucro e de uma maior competitividade, de fazer mais com menos, as instituições públicas e privadas justificam o forte investimento em tecnologia da informação (TI) como solução para todas as questões, deixando de lado os conceitos da gestão do conhecimento (GC) e ignorando áreas como a Ciência da Informação (CI) e a Arquivologia (INNARELLI, 2012).

Davenport (1998, p. 129) explica que "Criar uma cultura organizacional que valorize e ofereça oportunidades para a comunicação de conhecimento tácito é algo que não acontece com frequência.”. Quando esse conhecimento acumulado não é adequadamente gerido e compartilhado, o risco de perda aumenta exponencialmente. Daí a importância de uma boa gestão da informação, que vai se refletir diretamente no desempenho dos funcionários da instituição e que vai focar em transformar a informação em conhecimento de maneira sistematizada.

Para aquelas instituições que enxergam a informação como um ativo importante, a necessidade de gerir seus volumes informacionais e o conhecimento como potenciais estratégicos requer criação e atividades práticas para o desenvolvimento de uma política de gestão da informação (INNARELLI, 2012).

Analisar a informação organizacional em termos de necessidades, de busca e de uso da informação e propor um modelo de administração da informação foi a forma de Choo (2003) de demonstrar o ciclo contínuo de seis processos paralelos que ele sugere ver como "[...] uma rede de processos que adquirem, criam, organizam, distribuem e usam a informação.” (CHOO, 2003, p. 403). Esses processos podem ser observados na Figura 1. 
Figura 1 - Modelo processual de administração da informação

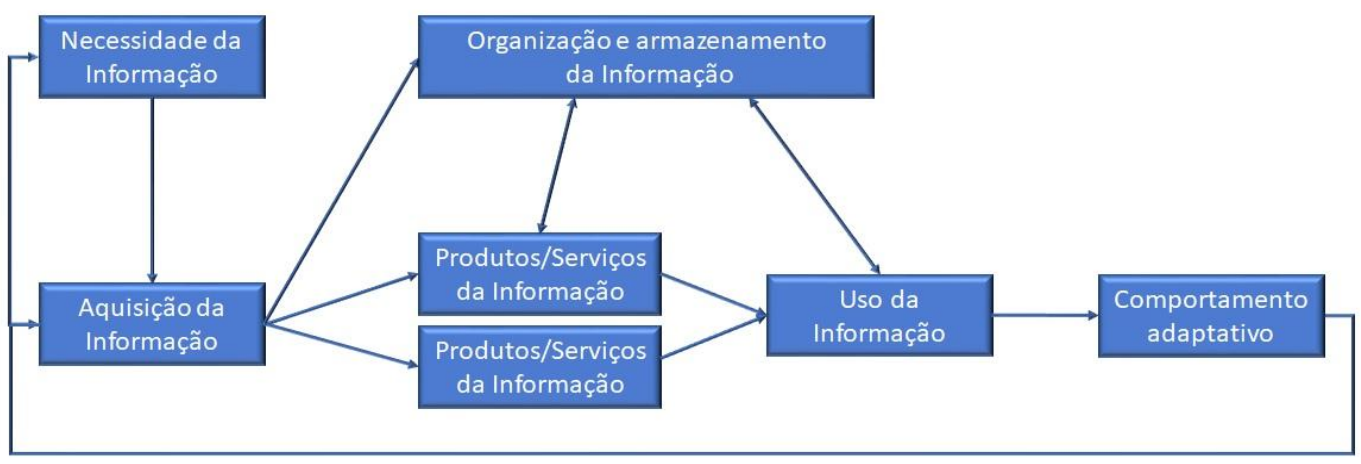

Fonte: Choo (2003, p. 404).

Esse modelo é proposto com o propósito de gerar estratégias de administração da informação; nele, a informação é elemento fundamental para a tomada de decisões dentro das organizações. Esse ciclo proporciona que decisões gerem novas informações, que quando registradas vão auxiliar decisões futuras. Assim, o ciclo se retroalimenta.

O processo de uso da informação é um instrumento ativo de descobertas. Em função da forma como essa informação for recebida, podem surgir várias interpretações em um mesmo contexto, já que cada indivíduo pensa e interpreta de forma particular. Isto posto, quanto maior for a troca de informações e a partilha de conhecimentos adquiridos, melhores serão as intervenções e decisões tomadas pela instituição, contribuindo para transformar a informação em conhecimento.

\section{Gestão de documentos: a informação nas instituições públicas}

Os arquivos têm como finalidade servir à administração de uma instituição e sua função básica é disponibilizar as informações do acervo que essa instituição mantém sob sua custódia. Para isso é necessário que os documentos sejam geridos de forma a atender as necessidades dos usuários, a fim de cumprir seu papel, seja ele social, administrativo e/ou jurídico, e é fundamental que as informações armazenadas nos arquivos estejam organizadas, preservadas e acessíveis (PAES, 2004). 
Os arquivos em ambiente analógico ou digital têm por objetivo organizar e preservar as informações e viabilizar o acesso a elas. A legislação arquivística no Brasil, na forma da Lei 8.159/1991, em seu art. $2^{\circ}$, considera arquivo

[...] os conjuntos de documentos produzidos e recebidos por órgãos públicos, instituições de caráter público e entidades privadas, em decorrência do exercício de atividades específicas, bem como por pessoa física, qualquer que seja o suporte da informação ou a natureza dos documentos. (BRASIL, 1991).

O que vai caracterizar um "documento arquivístico" é o fato de ser registrado, independentemente de suporte ou formato, e de tratar das funções e atividades desempenhadas por uma pessoa ou instituição - um documento com contexto e valor de prova (DURANTI,1994; BERNARDES, 2015). Duranti (1994), traz como características dos documentos arquivísticos a imparcialidade, a autenticidade, a naturalidade, o interrelacionamento e a unicidade.

Segundo Rousseau e Couture (1998, p. 52), os princípios arquivísticos são: o princípio da territorialidade, o princípio da proveniência (trata da ordem original e do respeito aos fundos) e a teoria das três idades (ciclo de vida dos documentos). Para os autores estes princípios "constituem o fundamento da disciplina" e "constituem a própria base da arquivística moderna". Os princípios arquivísticos são indispensáveis para a gestão dos documentos arquivísticos, pois asseguram a integridade documental.

A gestão de documentos surgiu com a necessidade de organizar e racionalizar a massa documental acumulada nas instituições, sejam estas públicas ou privadas. Além de ser um dos pilares para uma gestão pública transparente também tem como função social possibilitar o acesso à informação. A gestão de documentos é fator crucial para o desenvolvimento funcional de qualquer instituição, favorecendo a tomada de decisão (BERNARDES, 2015).

Nas instituições públicas é recorrente a preocupação com os acúmulos de massa documental, assim como, a falta de tratamento adequado desses acervos que guardam a memória destas instituições. Agora essa preocupação se estende aos documentos digitais, 
que demandam um cuidado ainda mais rigoroso visando garantir a confiabilidade, autenticidade e preservação desses documentos.

A Lei 8.159 de 8 de Janeiro de 1991, no que diz respeito ao seu Art. $1^{\text {o }}$ explicita que "É dever do Poder Público a gestão de documentos e a proteção especial a documentos de arquivos, como instrumento de apoio à administração, à cultura, ao desenvolvimento científico e como elementos de prova e informação”. (BRASIL, 1991).

Indolfo (2012, p. 16), atenta ao fato que, "não se pode falar de gestão de documentos como um conceito único e de aplicação universal”. Faz-se necessário pensar a gestão de documentos arquivísticos com base nas necessidades das instituições, o que vai resultar, inclusive, em redução de custos.

No atual cenário de processos de Transformação Digital nas instituições, faz-se necessária uma gestão arquivística de documentos que contemple também os documentos digitais, uma política e procedimentos de gestão de documentos de acordo com a legislação e resoluções estabelecidas, com um sistema eficiente, capaz de gerir os documentos digitais desde a produção até a sua destinação final contemplando estratégias de preservação a longo prazo. (BRASIL, 2004).

No âmbito normativo a Lei 12.527/2011, ao regulamentar o inciso XXXIII do Art. $5^{\circ}$ da Constituição Federal, torna efetivo o dever dos órgãos públicos darem acesso às informações a todos os cidadãos que o requererem e com prazo definido para a resposta "[...] sob pena de responsabilidade, ressalvadas aqueles cujo sigilo seja imprescindível à segurança da sociedade e do Estado". (BRASIL, 2011).

No contexto da arquivologia, Rousseau e Couture (1998), apresentam sete funções arquivísticas que estão presentes no processo de gestão de documentos: produção, avaliação, aquisição, conservação, classificação, descrição e difusão. Os autores explanam que para uma gestão de documentos eficaz, essas funções precisam estar interligadas.

Para Bernardes (2015), a avaliação é a mais estratégica das atividades da gestão de documentos, e Indolfo (2012), confirma essa característica estratégica da avaliação no controle do ciclo vital dos documentos arquivísticos. O processo de avaliação documental 


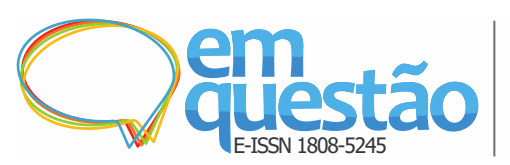

Diagnóstico do processo de implantação do INSS Digital: perspectivas e gestão da informação

Patrícia Soares Silva Bertotti, Ana Clara Cândido, Luciane Paula Vital

reside em identificar os valores e examinar o ciclo de vida dos documentos, visando estabelecer prazos para sua eliminação ou guarda permanente, auxiliando na administração e na preservação dos acervos. (BERNARDES, 1998).

Indolfo (2012, p. 21), explica que é indiscutível a necessidade da classificação para o processo de avaliação, e que "a transferência de documentos para os arquivos intermediários não deve ocorrer sem que estes tenham sido, anteriormente, avaliados", segundo a autora a união desses dois processos (classificação e avaliação) vai garantir o controle do ciclo de vida dos documentos.

A teoria das três idades trata do ciclo de vida dos documentos e é descrita por Bellotto (2006) da seguinte forma:1) idade corrente: nesta primeira idade estão os documentos de uso cotidiano, com prazos jurídicos e que são necessários ao funcionamento das instituições;2) idade intermediária, quando alcança a segunda idade: nesta fase encontram-se os documentos que já não possuem mais valor jurídico, mas que são ainda passíveis de uso pela instituição, ficam à disposição para eventuais consultas;3) idade permanente, quando atingida a terceira idade: nesta fase ocorre o "recolhimento" dos documentos para a guarda definitiva, iniciando seu uso científico, cultural e social.

Vale lembrar a importância de se continuar o processo de gestão de documentos no arquivo permanente, efetuando a preservação, conservação e a descrição dos documentos. Quanto à temporalidade e destinação de documentos de arquivo o CONARQ aborda o conceito da tabela de temporalidade e explicita o que deve contemplar a sua estrutura:

A tabela de temporalidade é um instrumento arquivístico resultante de avaliação, que tem por objetivos definir prazos de guarda e destinação de documentos, com vista a garantir o acesso à informação a quantos dela necessitem. Sua estrutura básica deve necessariamente contemplar os conjuntos documentais produzidos e recebidos por uma instituição no exercício de suas atividades, os prazos de guarda nas fases corrente e intermediária, a destinação final - eliminação ou guarda permanente -, além de um campo para observações necessárias à sua compreensão e aplicação (BRASIL 2001, p. 43). 
A tabela de temporalidade e a lista de eliminação são os dois instrumentos básicos de destinação e são definidos por Paes (2004, p. 106) como "atos normativos elaborados pelas comissões de análise, nos quais são fixadas as diretrizes quanto ao tempo e local de guarda dos documentos.”.

\section{A preservação digital no processo de transformação digital}

Percebe-se atualmente um grande debate em torno da digitalização na literatura da CI e nas organizações. De forma geral, ocorrem com muita frequência, devido às mudanças tecnológicas e à necessidade das instituições de acompanhar esse novo processo denominado "Transformação Digital" (MENDONÇA; ZAIDAN, 2019). Porém, é necessário pensar nas consequências desse processo. Os autores ressaltam o fato de haver muito interesse no tema, mas ainda muito poucos trabalhos desenvolvidos. Tolboom (2016, p. 7, tradução nossa) define transformação digital como "[...] uma mudança social, móvel, analítica ou induzida por nuvem que afeta três ou mais dimensões em nível individual, empresarial e/ou social.”. A transformação digital para o INSS representa um momento de transição no trato documental, um momento em que os processos deixam de tramitar no formato analógico e passam a existir no modelo digital. Trata-se de uma profunda mudança cultural e comportamental para a instituição.

A grande questão atual é como convencer as instituições de que neste processo de transformação digital, é de fato importante planejar e aplicar uma preservação digital a longo prazo. O documento arquivístico digital possui caraterísticas específicas e mais complexas, que demandam um tratamento diferente do que se dá aos documentos analógicos. As instituições precisam elaborar um planejamento que contemple a preservação digital de seus documentos e para isso faz-se necessária a definição de uma política de preservação, visando garantir a confiabilidade de seus repositórios digitais. (SANTOS; FLORES, 2015).

O grande desafio da preservação digital consiste em garantir a autenticidade e acesso a longo prazo dos documentos. Nesse contexto o e-ARQ Brasil indica os 
requisitos mínimos necessários para o funcionamento de um Sistema Informatizado de Gestão Arquivística de Documentos. (SIGAD):

\begin{abstract}
Considerando-se que os documentos arquivísticos se constituem, primeiramente, em instrumentos fundamentais para a tomada de decisão e para a prestação de contas de órgãos ou entidades, e, num segundo momento, em fontes de prova, garantia de direitos aos cidadãos e testemunhos de ação, faz-se necessária a adoção de procedimentos rigorosos de controle para garantir a confiabilidade e a autenticidade desses documentos, bem como o acesso contínuo a eles. Isso só é possível com a implantação de um programa de gestão arquivística de documentos (BRASILCONSELHO NACIONAL DE ARQUIVOS (Brasil), 2011 p. 16).
\end{abstract}

Para Santos e Flores (2015, p. 213), “A custódia confiável torna-se um requisito para a preservação em longo prazo [...].”. Os autores atentam para a necessidade de manter uma interoperabilidade entre as tecnologias e afirmam que para preservar os documentos digitais, a instituição deverá levar em conta as normas, as recomendações e os padrões existentes, começando por definir uma política de preservação, assegurando confiabilidade e estabilidade ao repositório digital.

Deixar de investir em preservação digital poderá resultar em problemas, por isso faz-se necessária a adoção de plataformas de gestão e de acesso, como também é fundamental contemplar um ambiente de preservação. Somente por meio da preservação ininterrupta e interoperada mitigaremos os riscos de obsolescência tecnológica e alterações indevidas, entre outros riscos. (FLORES, 2016).

Lehmkuhl, Macedo e Silva (2018) explicam que no Brasil os Repositórios Arquivísticos Digitais Confiáveis (RDC-Arq) são reconhecidos como repositórios que atendem às normativas específicas e que não se pode falar em uma forma exclusiva e definitiva de preservar os documentos em ambiente digital. Esses autores ponderam, porém, que aplicando-se métodos e recursos reconhecidos, é possível conduzir uma adequada preservação evitando colocar em risco o acesso aos documentos a longo prazo. Os autores também registram que essa condição de repositório arquivístico digital confiável é dada pela Resolução n 43/2015, do CONARQ (BRASIL, 2015), que 
determina que esses repositórios, além de atender aos requisitos de um repositório confiável, devem atender a metodologias arquivísticas relativas a todo ciclo de vida dos documentos.

De fato, o que a resolução nos traz é a definição de uma cadeia de custódia completa e ininterrupta para os documentos digitais, que atenda desde a produção desses documentos até sua destinação final, por meio de um SIGAD, que inclua sua preservação permanente através de um repositório digital confiável, a exemplo do Archivematica, e que garanta seu acesso por meio de uma plataforma segura, como o AtoM, autêntica e integrada ao RDC-Arq. (LEHMKUHL; MACEDO; SILVA, 2018).

A Figura 2 mostra os três ambientes da cadeia de custódia de documentos digitais, ambiente de gestão, preservação e acesso.

Figura 2 - Cadeia de custódia de documentos digitais

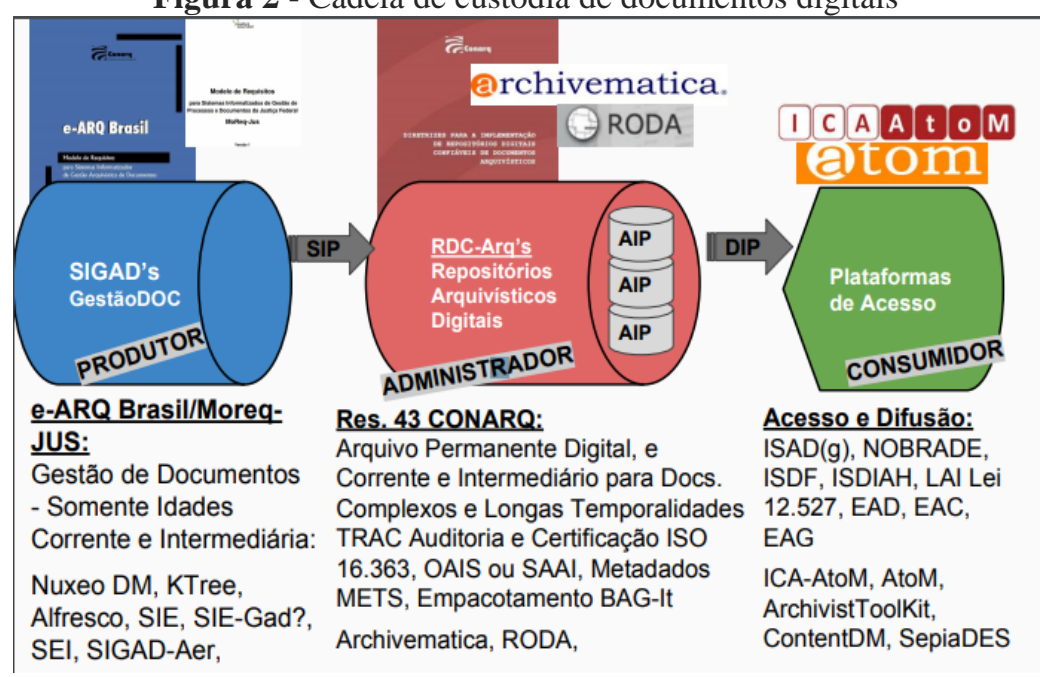

Fonte: Flores (2016).

A gestão de documentos arquivísticos não decorre do suporte no qual a informação está registrada; é um procedimento indispensável e que deve ser norteado pelos conceitos e teorias difundidas pela Arquivologia. (DURANTI, 1994). 


\section{Procedimentos metodológicos}

O presente estudo é uma pesquisa qualitativa, de caráter exploratório, que tem como objetivo aprofundar o conhecimento de um tema específico, buscando uma aproximação com a temática; é também descritivo, a partir de uma análise detalhada que visa descrever as características e facilitar a compreensão do assunto (CERVO; BERVIAN; SILVA, 2007). Foi feito um estudo de caso aplicado, no qual foram utilizados dados primários e secundários, com o objetivo de examinar um fenômeno contemporâneo dentro do seu contexto factual (YIN, 2001).

A análise de conteúdo é utilizada para a interpretação dos resultados, a partir de categorias apresentadas a seguir. De acordo com Bardin (2016), a análise de conteúdo é bastante dependente do material a ser analisado e do objetivo a ser alcançado.

\subsection{Instrumentos de coleta de dados}

Os procedimentos metodológicos foram norteados pelo levantamento de dados de fontes primárias, por meio de questionários com os quais se buscou uma melhor compreensão acerca do processo de transformação digital do INSS, e de dados secundários referentes a documentos da própria instituição, como artigos e material online disponível no site da autarquia.

O principal instrumento para coleta de dados desta pesquisa foram questionários enviados à instituição: ao Serviço de Informação ao Cidadão (e-SIC) do INSS, à Divisão de Gestão de Documentação e Informação do INSS e aos servidores técnicos de duas agências do INSS. Esses questionários foram elaborados a partir do conhecimento do atual cenário da instituição comparado ao que está descrito na literatura existente no que diz respeito à gestão da informação; na literatura, destacam-se Davenport (1998), Choo (2003) e Innarelli (2012), entre outras referências.

Inicialmente foi realizada uma fase de pré-teste com servidores da Superintendência Regional em Florianópolis, o que possibilitou ajustes para aplicação do questionário final. Dos questionários enviados, o primeiro foi online, direcionado à página do e-SIC do INSS referente às informações atualizadas da gestão de documentos 
após a implantação do novo sistema de atendimento e ao tratamento desse acervo documental. Esse questionário enviado ao e-SIC foi aplicado com base na Lei de Acesso à Informação (LAI) e enviado à instituição por meio do Portal da Transparência, seguindo seus trâmites. As questões foram enviadas diretamente ao e-SIC, em 24 de junho de 2019, às 19h17, e foi gerado o protocolo de número 03006002535201971. O prazo de resposta foi prorrogado e as respostas foram disponibilizadas no dia 16 de julho de 2019.

Dando continuidade à coleta de dados, um segundo questionário foi enviado, pelo e-mail disponibilizado pela instituição, à Divisão de Gestão de Documentação e Informação do INSS, localizado na Administração Central em Brasília, Distrito Federal.

Foi enviado ainda um terceiro questionário, este online, destinado aos servidores técnicos de duas agências do INSS, uma no estado do Rio Grande do Sul e outra no estado de Santa Catarina, buscando detectar pontos relevantes e compreender melhor o entendimento daqueles que trabalham em nível operacional diretamente com as demandas dos cidadãos nesse novo modelo de atendimento. Optou-se aleatoriamente por trabalhar com duas agências da região Sul, uma no interior de seu estado e outra na capital de seu estado, buscando identificar como as informações chegam a esses servidores.

\subsection{Análise de conteúdo}

Após a aplicação dos três questionários, as informações foram categorizadas conforme os pressupostos da análise de conteúdo. Foram delimitadas quatro categorias com base nos termos intrínsecos observados nas respostas obtidas e os resultados foram agrupados de acordo com o tema a que se referiam.

\subsubsection{Categorias de análise}

Definir as categorias de uma análise é agrupar seus elementos segundo suas diferenças para, em seguida, agrupá-los novamente seguindo critérios preestabelecidos. Essas categorias, então, serão compostas por elementos agrupados em razão dos elementos 
comuns entre eles, sob um título que as identifique. $\mathrm{O}$ ato de agrupar esses elementos em uma categoria requer do analista um exame mais atento sobre o que eles têm, de fato, em comum. (BARDIN, 2016).

Neste estudo as respostas foram analisadas em conjunto. Foram definidas categorias para nortear a análise das respostas dadas aos questionários aplicados. São elas: a) política de preservação digital; b) gestão de documentos dos procedimentos técnicos internos; c) sistema de informação; d) desafios ao gerenciamento de informação.

\section{Resultados a partir das categorias de análise}

Quanto às informações da gestão de documentos, após a implantação do novo sistema de atendimento, e quanto ao tratamento do acervo documental, indagou-se pela observância, com a consolidação do INSS Digital, às normas do CONARQ de preservação, guarda e recuperação das informações (metadados estabelecidos) dos segurados, e também se perguntou se existia uma política de preservação digital estabelecida na instituição, conforme se observa no Quadro 1.

Quadro 1 - Respostas referentes à política de preservação digital

\begin{tabular}{|l|l|}
\hline Resposta & $\begin{array}{l}\text { Não há estrita observância às normas do CONARQ, no entanto a preservação, guarda e } \\
\text { recuperação das informações dos segurados se limita ao estabelecido pela segurança e } \\
\text { dos Datacenters gerenciados pela DATAPREV - Empresa de Tecnologia e Informações } \\
\text { da Previdência Social, bem como pelas funcionalidades dos Sistemas finalísticos do } \\
\text { INSS. }\end{array}$ \\
\hline Resposta & Atualmente não há uma política de preservação digital. \\
\hline Resposta & $\begin{array}{l}\text { Depende do tipo de arquivo gerado, mas normalmente utiliza-se número do benefício, } \\
\text { espécie do documento ou nome do cidadão. [...] anexados em formato PDF. }\end{array}$ \\
\hline Resposta & $\begin{array}{l}\text { Os docs são digitalizados e os anexos incluídos no GET } \\
\text { utilização. a fim de visualização e }\end{array}$ \\
\hline
\end{tabular}

Fonte: Elaborado pelas autoras (2019).

Esta situação se aproxima da constatação de Innarelli (2012) no que tange ao desafio de convencer as instituições da importância de planejar adequadamente a implantação de um processo de preservação digital a longo prazo neste momento de transformação digital pelo qual essas instituições passam. Segundo esse autor, a adoção 
de política de preservação, associada ao uso da tecnologia, é a forma de garantir a preservação dos documentos digitais a longo prazo.

Observando os resultados da pesquisa, é possível perceber certo empirismo no trato documental e a urgência de uma reflexão acerca das melhorias que ainda precisam ocorrer para que o INSS Digital não corra o risco de prejudicar a memória organizacional da instituição. Observa-se a necessidade de uma maior atenção a normas e estudos sobre preservação digital; essa maior atenção resultará em um melhor atendimento e assegurará o reconhecimento dos direitos dos contribuintes e segurados.

A Portaria $n^{\circ} 1.106$ de 30 de junho de 2017 dispõe sobre procedimentos para expansão do projeto INSS Digital. A partir desse documento, é possível uma breve análise do que acontece hoje com os arquivos digitais do INSS. A portaria indica que todos os documentos que os segurados enviam ao requerer um benefício devem ser escaneados e salvos, de forma contínua, em formato PDF - Portable Document Format (apenas PDF) 24 bits colorido e qualidade 150 DPI. Isso significa que um arquivo PDF associado a um requerimento do Gerenciador Eletrônico de Tarefas (GET) pode conter vários documentos, pois a orientação é que, sempre que possível, os documentos deverão ser digitalizados em um arquivo único. Cada arquivo digitalizado recebe um nome padrão que o associa ao requerimento e a uma tarefa a ser executada. Todavia, estão normatizados 3 (três) padrões de nomes para um mesmo tipo de arquivo (BRASIL, 2017).

Os padrões de nomenclatura foram estabelecidos conforme o tipo de identificação dada aos documentos digitalizados, conforme o Quadro 2 ilustra.

Quadro 2 - Padrão de nomenclatura dos documentos digitalizados

\begin{tabular}{|l|l|}
\hline Original & NOME DO REQUERENTE_99999999999_ORIGINAIS.pdf \\
\hline Autenticação feita por terceiros & NOME DO REQUERENTE_99999999999_TERCEIROS.pdf \\
\hline Cópia simples & NOME DO REQUERENTE_99999999999_SIMPLES.pdf \\
\hline
\end{tabular}

Fonte: Elaborado com base na Portaria nº 1.106 de 30 de junho de 2017.

Não há, dessa forma, como precisar quantos documentos existem digitalizados e armazenados no GET. Os arquivos gerados são um tanto genéricos: utilizam-se nome e 
Cadastro de Pessoa Física (CPF) dos requerentes sem que se indique, contudo, o que de fato contém cada arquivo, pois não se utilizam metadados.

Quanto à gestão de documentos dos procedimentos técnicos internos, a implantação do modelo de atendimento baseado no processo digital trouxe a necessidade de criar, também, uma nova forma de analisar os processos e a documentação que lhe servem de subsídio, uma vez que não é mais feita uma análise física dos documentos. Perguntou-se à instituição de que forma ela recebe e guarda a documentação física dos requerentes no ato de solicitação de benefícios, agora no modelo digital, e também como ela gere os documentos físicos sob sua guarda até a virada para o modelo digital. O Quadro 3 mostra as respostas.

Quadro 3 - Respostas relativas à categoria gestão de documentos dos procedimentos técnicos internos

\begin{tabular}{|l|l|}
\hline Resposta & $\begin{array}{l}\text { Todos os documentos (independente de concessão automática ou não) são armazenados } \\
\text { nos Datacenters gerenciados pela DATAPREV - Empresa de Tecnologia e Informações } \\
\text { da Previdência Social, com critérios de preservação, guarda e recuperação das } \\
\text { informações próprios do Datacenter. }\end{array}$ \\
\hline Resposta & $\begin{array}{l}\text { A documentação física é arquivada nos arquivos setoriais correntes e posteriormente } \\
\text { transferidas [sic] para os Centros de Documentação Previdenciária - CEDOCPREV's } \\
\text { que arquiva, gerencia, recupera e disponibiliza [sic] a documentação seja por meio digital } \\
\text { (digitalização sob demanda) ou fisicamente. }\end{array}$ \\
\hline
\end{tabular}

Fonte: Elaborado pelas autoras (2019).

A Resolução no 20 de 2004 do CONARQ dispõe sobre a necessidade de uma gestão arquivística dos documentos dos órgãos. Em seu artigo $2^{\circ}$, resolve: "Um programa de gestão arquivística de documentos é aplicável independente da forma ou do suporte, em ambientes convencionais, digitais ou híbridos em que as informações são produzidas e armazenadas." (BRASIL, 2004).

Considerando-se as respostas obtidas, percebe-se claramente que se adota fluxo de tratamento da documentação diverso daquele determinado pelo CONARQ, especialmente a partir da implantação do INSS Digital. Isso deixa muito clara a fragilidade a que os documentos digitais estão expostos em função da não adoção de uma cadeia de custódia completa. No que tange à preservação dos documentos físicos, percebe-se um fluxo e uma preocupação condizentes com o que é estabelecido, com muito ainda a ser 
melhorado, mas com uma probabilidade muito maior e mais segura de recuperação da informação.

No que tange à categoria de análise sistema de informação, a referida alteração no método de análise documental, do analógico para o digital, traz uma nova demanda para a instituição, qual seja, preservar digitalmente esse novo acervo. Nesse sentido, quando se questionou cada instituição sobre a adoção de sistemas de gerenciamento e preservação digital, obtiveram-se respostas que indicam a ausência de sistemas específicos para essa finalidade, conforme demonstrado no Quadro 4.

Quadro 4 - Respostas referente à categoria sistema de informação

\begin{tabular}{|l|l|}
\hline Respostas & $\begin{array}{l}\text { Todos os documentos (independente de concessão automática ou não) são armazenados } \\
\text { nos Datacenters gerenciados pela DATAPREV - Empresa de Tecnologia e Informações da } \\
\text { Previdência Social, com critérios de preservação, guarda e recuperação das informações } \\
\text { próprios do Datacenter. }\end{array}$ \\
\hline Respostas & $\begin{array}{l}\text { Não. Ainda não possuímos uma gestão efetiva de documentos digitais, pois precisamos de } \\
\text { um sistema informatizado de gestão arquivística de documentos digitais - SIGAD e um } \\
\text { repositório digital confiável - RDCArq. }\end{array}$ \\
\hline Respostas & Até onde sei a gestão se dá pelo sistema GET. \\
\hline
\end{tabular}

Fonte: Elaborado pelas autoras (2019).

Para Santos e Flores (2015, p. 213), “A custódia confiável torna-se um requisito para a preservação em longo prazo [...].”. Os autores advertem que para preservar documentos digitais, é fundamental considerar as normas, recomendações e padrões existentes, a começar pela definição de uma política de preservação digital adequada, que garanta um repositório digital confiável e cujas tecnologias estejam interoperadas. Innarelli (2012) atenta para o fato de que as instituições, em busca de fazer mais com menos, investem fortemente em tecnologia da informação, deixando de lado áreas como Ciência da Informação e Arquivologia.

Paralelos ao processo de transformação digital, existem outros processos tão importantes quanto ele ou mesmo mais importantes que ele: a capacitação para a nova realidade tecnológica, a reestruturação do INSS, a gestão e a preservação documental e a redução drástica do quadro funcional são processos cuja informação não circula com a 
mesma clareza e intensidade. Com isso, fica evidente também uma tendência ao modelo anárquico de política de informação, no qual não há um padrão estabelecido de gerenciamento das informações e no qual cada unidade cria e gerencia suas próprias informações, o que cria uma série de problemas no processo de gestão.

No que tange aos desafios recorrentes quanto à gestão da informação dessa instituição, questões relativas ao quadro funcional, capacitações dos servidores para desempenhar suas funções dentro da nova realidade e ainda para enfrentar o crescente número de aposentarias evidenciam o prejuízo no repasse de conhecimento aos remanescentes. O primeiro mês do ano já insinuava o que poderia vir a ser 2019 para o INSS em termos de recursos humanos. Segundo a Associação Nacional dos Servidores da Previdência Social -(ANASPS), o início do ano de 2019 apresentou um acréscimo significativo na saída de servidores, totalizando, apenas no mês de janeiro de 2019, 676 servidores aposentados contra 166 servidores no mesmo período de 2018, um incremento nas aposentadorias superior a 300\%. (ASSOCIAÇÃO NACIONAL DOS SERVIDORES DA PREVIDÊNCIA SOCIAL, 2019). Segundo a mesma associação, até julho de 2019, somente no Ministério da Economia, ministério ao qual está ligado o INSS, foram concedidas 7.730 aposentadorias a servidores.

Comparando-se o modelo de administração da informação proposto por Choo (2003) com o que se passa no INSS, vê-se que no INSS existe a necessidade da informação, porém a aquisição não ocorre de forma contínua, o que compromete as próximas fases, conforme se percebe na Figura 3.

Figura 3 - Modelo processual de administração da informação no INSS

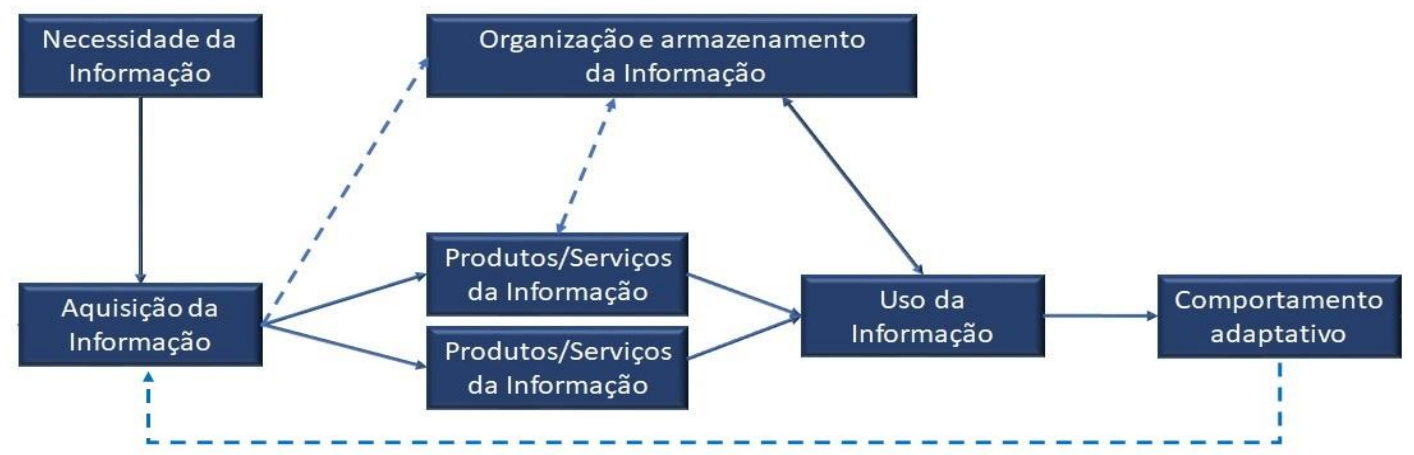


Fonte: Elaboração própria baseada no modelo de administração da informação de Choo (2003).

No caso do INSS, a necessidade gera a aquisição de informação, que gera produtos e serviços a partir dessa informação, os quais, uma vez utilizados, criam um comportamento adaptativo. Esse comportamento adaptativo é uma forma eventual de aquisição da informação ("fulano faz assim, vou fazer igual"). Porém, nem toda a informação adquirida é organizada e armazenada. Nem toda informação armazenada gera produtos e serviços e vice-versa. A informação armazenada apenas alimenta o uso.

Por fim, ao relacionarem-se as respostas fornecidas pela administração central e pelos servidores de nível operacional, percebe-se que não existe um fluxo de informação claro entre eles. A gestão da informação na instituição não está ocorrendo de forma adequada, o que compromete a qualidade nos serviços prestados aos cidadãos. Com relação ao cumprimento dos normativos que embasam o objeto de estudo deste trabalho, apresenta-se no Quadro 5 a situação da autarquia até o presente momento.

\begin{tabular}{|c|c|c|}
\hline Norma & Ementa & $\begin{array}{c}\text { Situação no } \\
\text { INSS Digital }\end{array}$ \\
\hline Lei 5.433/1968 & $\begin{array}{l}\text { Regula a microfilmagem de documentos oficiais e dá } \\
\text { outras providências. (BRASIL, 1968). }\end{array}$ & Não cumprida \\
\hline Lei 8.159/1991 & $\begin{array}{l}\text { Dispõe sobre a política nacional de arquivos públicos e } \\
\text { privados e dá outras providências. (BRASIL, 1991). }\end{array}$ & Não cumprida \\
\hline $\begin{array}{l}\text { Lei 12.527/2011 } \\
\text { - LAI }\end{array}$ & $\begin{array}{l}\text { Regula o acesso a informações previsto no inciso XXXIII } \\
\text { do art. } 5^{\circ} \text {, no inciso II do } \S 3^{\circ} \text { do art. } 37 \text { e no } \S 2^{\circ} \text { do art. } \\
216 \text { da Constituição Federal; [...] e dá outras providências. } \\
\text { (BRASIL, 2011). }\end{array}$ & Cumpre \\
\hline Lei $12.682 / 2012$ & $\begin{array}{l}\text { Dispõe sobre a elaboração e o arquivamento de } \\
\text { documentos em meios eletromagnéticos. Alterada pela Lei } \\
\text { 13.874/2019. (BRASIL, 2012). }\end{array}$ & Não cumprida \\
\hline Lei 13.874/2019 & $\begin{array}{l}\text { Institui a Declaração de Direitos de Liberdade Econômica; } \\
\text { estabelece garantias de livre mercado [...] e dá outras } \\
\text { providências. (BRASIL, 2019). }\end{array}$ & $\begin{array}{l}\text { Recentemente } \\
\text { aprovada. } \\
\text { Ainda não } \\
\text { aplicada. }\end{array}$ \\
\hline $\begin{array}{l}\text { Decreto } \\
4073 / 2002\end{array}$ & $\begin{array}{l}\text { Regulamenta a Lei } \mathrm{n}^{\circ} 8.159 \text {, de } 8 \text { de janeiro de } 1991 \text {, que } \\
\text { dispõe sobre a política nacional de arquivos públicos e } \\
\text { privados. (BRASIL, 2002). }\end{array}$ & Não cumprida \\
\hline $\begin{array}{l}\text { Decreto } \\
8936 / 2016\end{array}$ & $\begin{array}{l}\text { Institui a Plataforma de Cidadania Digital e dispõe sobre a } \\
\text { oferta dos serviços públicos digitais, no âmbito dos órgãos } \\
\text { e das entidades da administração pública federal direta, } \\
\text { autárquica e fundacional. (BRASIL, 2016). }\end{array}$ & Cumpre \\
\hline
\end{tabular}




\begin{tabular}{|c|c|c|}
\hline $\begin{array}{l}\text { Portaria } \\
1106 / 2017\end{array}$ & $\begin{array}{l}\text { Dispõe sobre procedimentos para expansão do Projeto } \\
\text { INSS Digital - Uma nova forma de atender. (BRASIL, } \\
\text { 2017). }\end{array}$ & Cumpre \\
\hline $\begin{array}{l}\text { Resolução } \\
\text { n }^{\circ} \mathbf{2 0 / 2 0 0 4} \\
\text { CONARQ }\end{array}$ & $\begin{array}{l}\text { Dispõe sobre a inserção dos documentos digitais em } \\
\text { programas de gestão arquivística de documentos dos } \\
\text { órgãos e entidades integrantes do Sistema Nacional de } \\
\text { Arquivos. (BRASIL, 2004). }\end{array}$ & Não cumprida \\
\hline $\begin{array}{l}\text { Resolução } \\
\text { no } 37 / 2012 \\
\text { CONARQ }\end{array}$ & $\begin{array}{l}\text { Aprova as Diretrizes para a Presunção de Autenticidade de } \\
\text { Documentos Arquivísticos Digitais. (BRASIL, 2012). }\end{array}$ & Não cumprida \\
\hline $\begin{array}{l}\text { Resolução } \\
\text { n'43/2015 } \\
\text { CONARQ }\end{array}$ & $\begin{array}{l}\text { Altera resolução de } n^{0} \text { 39/2014; Estabelece diretrizes para a } \\
\text { implementação de repositórios digitais confiáveis (RDC- } \\
\text { Arq - ISO } 16363 \text { norma internacional). (BRASIL, 2015). }\end{array}$ & Não cumprida \\
\hline $\begin{array}{l}\text { Nota Técnica } \\
03 / 2015 \\
\text { CONARQ }\end{array}$ & $\begin{array}{l}\text { Apresenta cenários que representam algumas } \\
\text { possibilidades de implantação de um Repositório } \\
\text { Arquivístico Digital Confiável (RDC-Arq) integrado a um } \\
\text { Sistema Informatizado de Gestão Arquivística de } \\
\text { Documentos (SIGAD). (BRASIL, 2015). }\end{array}$ & Não cumprida \\
\hline
\end{tabular}

Fonte: Elaborado pelas autoras (2019).

Pode-se perceber como é incipiente a adesão da autarquia aos normativos que regem a gestão de documentos; essa adesão limita-se aos normativos que instituem políticas de governo.

\section{Considerações finais}

Em janeiro de 2017 foi iniciado o processo de implantação do INSS Digital, um marco histórico para a maior autarquia do governo federal. Todos os benefícios pagos pelo INSS são baseados em documentação comprobatória da vida laboral dos requerentes. Essa documentação fica sob guarda do requerente e é apresentada ao INSS no momento de requerer o benefício, basicamente para ajustes e comprovação de períodos que, porventura, não estejam registrados no cadastro.

Este estudo buscou apresentar um diagnóstico do atual cenário da instituição e os procedimentos adotados a partir do início do processo de transformação digital, no sentido de gerir, preservar e manter acessível a documentação digital produzida a partir de então. Buscou-se saber os sistemas utilizados para fazer a gestão e a preservação digital dos documentos e conhecer o impacto dessas mudanças no dia a dia da autarquia e, ainda, identificar eventuais perspectivas para a gestão da informação. Para tanto 


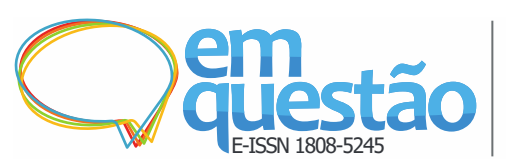

Diagnóstico do processo de implantação do INSS Digital: perspectivas e gestão da informação

Patrícia Soares Silva Bertotti, Ana Clara Cândido, Luciane Paula Vital

questionários foram elaborados e enviados tanto para o setor responsável pela gestão de documentos da autarquia quanto para servidores técnicos, que operacionalizam o processo de gestão de documentos, sendo a interface com o público.

O que foi possível depreender da análise foi uma expressiva falta de comunicação entre os setores da instituição. Os servidores da ponta não têm a informação exata e precisa de onde estão guardados esses arquivos, de quais são as garantias para sua preservação ao longo do tempo e de como se deve proceder a sua recuperação imediata e integral, porque não há um SIGAD. Além de não haver um SIGAD, existem, ainda, outros riscos a considerar, como vírus, falta de espaço ou mesmo falha no envio. Constata-se, assim, a inexistência de ações relativas à gestão de documentos. O INSS Digital não faz a gestão efetiva de seus documentos e, como não faz essa gestão, também não prepara seus servidores para isso.

Há, no processo de implantação do INSS Digital, uma clara confusão entre o papel da tecnologia da informação e o da gestão de documentos; basta observar as respostas dadas pelo setor responsável pela gestão de documentos da instituição. Não há uma política de gestão de documentos implantada, sendo tudo armazenado em datacenters sem a observância de qualquer noção arquivística, o que garantiria à instituição o desenvolvimento de uma gestão de documentos eficiente e capaz de promover uma preservação digital a longo prazo e com a garantia de autenticidade dos seus documentos.

Neste sentido evidenciam-se as perspectivas de gestão da informação no processo de transformação digital no INSS e fica clara a necessidade real e imediata de a instituição adotar uma política de gestão que contemple todos os aspectos, desde a produção dos documentos até sua destinação final, e que seja capaz de preservar os documentos digitais a longo prazo. Abre-se, dessa forma, um leque de oportunidades no campo da Arquivologia, da qual a instituição pode valer-se, no momento de transformação digital pelo qual passa, para fazer uma adequada gestão de suas informações. 


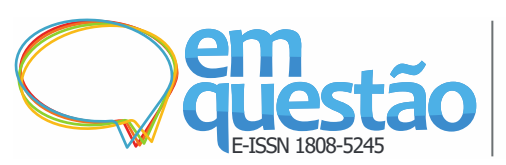

Diagnóstico do processo de implantação do INSS Digital: perspectivas e gestão da informação

Patricia Soares Silva Bertotti, Ana Clara Cândido, Luciane Paula Vital

No que tange à gestão de documentos, o caminho trilhado segue a mesma lógica da preservação digital. A instituição adota procedimentos diversos daqueles amplamente recomendados e normatizados pelo CONARQ e deixa de aproveitar o momento pelo qual está passando para adotar procedimentos técnicos amplamente reconhecidos para garantir a confiabilidade e autenticidade dos documentos. Ao invés disso, como se pode observar pelas respostas obtidas, faz a clássica confusão de atribuições e entrega a gestão de documentos para a tecnologia da informação, o que nos remete ao problema dos sistemas de informação.

Os sistemas adotados para fazer a "guarda" dos documentos digitais e digitalizados, na verdade, representam um risco a mais para a instituição. A própria autarquia admite não adotar SIGAD construído em conformidade com o que está normatizado pelo CONARQ nem fazer uso de um adequado RDC-Arq para a preservação da massa documental digital, que cresce a cada dia.

Posto isso, este trabalho abordou um manancial de situações que merecem estudos futuros mais aprofundados, a fim de que se certifique como evolui a situação da memória organizacional da instituição, que se demonstrou, a partir deste diagnóstico inicial, estar em iminente risco.

\section{Referências}

ASSOCIAÇÃO NACIONAL DOS SERVIDORES DA PREVIDÊNCIA SOCIAL. Número de aposentadorias de servidores do INSS quadruplica. 2019. Disponível em: https://www.anasps.org.br/numero-de-aposentadorias-de-servidores-doinss-quadruplica/. Acesso em: 02 ago. 2019.

BARDIN, L. Análise de conteúdo. São Paulo: Edições 70, 2016. 279 p.

BELlOTTO, H. L. Arquivos permanentes: tratamento documental. 4. ed. Rio de Janeiro: Editora FGV, 2006.

BERNARDES, I. P. Como avaliar documentos de arquivo. São Paulo: Arquivo do Estado de São Paulo, 1998. 89 p. Coleção Como Fazer 1. 
BERNARDES, I. P. gestão de documentos e direito de acesso: interfaces. Acervo Revista do Arquivo Nacional, Rio de Janeiro, v. 28 No 2 jul. n. 2, p. 164-179, dez, 2015.

BRASIL. Lei n. 5433, de 08 de maio de 1968. Regula a microfilmagem de documentos oficiais e dá outras providências. Brasília, DF: Diário Oficial da União, 1968. Disponível em: http://www.planalto.gov.br/ccivil_03/LEIS/L5433.htm. Acesso em: 14 abr. 2019.

BRASIL. Constituição (1988). Constituição da República Federativa do Brasil de 1988. Brasília, DF: Presidência da República. Disponível em:

http://www.planalto.gov.br/ccivil_03/Constituicao/Constituicao.htm\#art5xxxiii. Acesso em: 05 nov. 2020.

BRASIL. Lei n. 8.159, de 8 de janeiro de 1991. Dispõe sobre a política nacional de arquivos públicos e privados e dá outras providências. Brasília, DF: Diário oficial da União, 1991. Disponível em: http://www.planalto.gov.br/ccivil_03/leis/L8159.htm. Acesso em: 08 abr. 2019.

BRASIL. Conarq. Classificação, temporalidade e destinação de documentos de arquivo relativos às atividades-meio da administração pública. Rio de janeiro: Arquivo Nacional, 2001. Disponível em: http://www.siga.arquivonacional.gov.br/images/publicacoes/cctt_meio.pdf. Acesso em: 8 mar. 2019.

BRASIL. Decreto $\mathbf{n}^{\mathbf{0}}$ 4073, de 03 de janeiro de 2002. Regulamenta a Lei no 8.159, de 8 de janeiro de 1991, que dispõe sobre a política nacional de arquivos públicos e privados. Brasília, DF: Diário Oficial da União, 2002. Disponível em: http://www.planalto.gov.br/ccivil_03/decreto/2002/d4073.htm. Acesso em: 16 abr. 2019.

BRASIL. Conarq. Resolução no 20 de 16 de junho de 2004. Dispõe sobre a inserção dos documentos digitais em programas de gestão arquivística de documentos dos órgãos e entidades integrantes do Sistema Nacional de Arquivos. Disponível em:

http://www.conarq.gov.br/resolucoes-do-conarq/262-resolucao-n-20,-de-16-de-julho-de2004.html. Acesso em: 28 mar. 2018

BRASIL. A. N. Dicionário brasileiro de terminologia arquivística. Rio de Janeiro: Arquivo Nacional, 2005.

BRASIL. Lei $\mathbf{n}^{0}$ 12527/2011, de 18 de novembro de 2011. Regula o acesso a informações previsto no inciso XXXIII do art. $5^{\circ}$, no inciso II do $\S 3^{\circ}$ do art. 37 e no $\S 2^{\circ}$ do art. 216 da Constituição Federal; e dá outras providências. Brasília, DF: Diário Oficial da União, 2011. Disponível em: http://www.planalto.gov.br/ccivil_03/_ato20112014/2011/lei/112527.htm. Acesso em: 15 abr. 2019. 
Diagnóstico do processo de implantação do INSS Digital: perspectivas e gestão da informação

Patrícia Soares Silva Bertotti, Ana Clara Cândido, Luciane Paula Vital

BRASIL. Lei no 12682, de 09 de julho de 2012. Dispõe sobre a elaboração e o arquivamento de documentos em meios eletromagnéticos. Brasília, DF: Diário Oficial da União, 2012. Disponível em: http://www.planalto.gov.br/ccivil_03/_ato20112014/2012/lei//12682.htm. Acesso em: 15 abr. 2019.

BRASIL. Resolução no 37, de 19 de dezembro de 2012. Aprova as Diretrizes para a Presunção de Autenticidade de Documentos Arquivísticos Digitais. Brasília, DF: Diário Oficial da União, 2014. Disponível em: http://www.conarq.gov.br/resolucoes-doconarq/279-resolucao-n-37,-de-19-de-dezembro-de-2012.html. Acesso em: 16 abr. 2019.

BRASIL. Nota Técnica $\mathbf{n}^{\mathbf{0}}$ 3, de novembro de 2015. Cenários de uso de RDC-Arq em conjunto com o SIGAD. Conselho Nacional de Arquivos Câmara Técnica de Documentos Eletrônicos: Orientação Técnica n. ${ }^{\circ}$ 3. Disponível em:

http://www.conarq.gov.br/images/ctde/Orientacoes/Orientacao_tecnica_rdcarq_2015_v8 _pub.pdf. Acesso em: 18 abr. 2019.

BRASIL. Resolução $\mathbf{n}^{0}$ 43, de 04 de setembro de 2015. Altera a redação da Resolução do CONARQ n ${ }^{\circ} 39$, de 29 de abril de 2014, que estabelece diretrizes para a implementação de repositórios digitais confiáveis para a transferência e recolhimento de documentos arquivísticos digitais para instituições arquivísticas dos órgãos e entidades integrantes do Sistema Nacional de Arquivos - SINAR. Arquivo Nacional Conselho Nacional de Arquivos: RESOLUÇÃO N 43, DE 04 DE SETEMBRO DE 2015. Brasília, DF: Diário Oficial da União, 2015. Disponível em:

http://conarq.arquivonacional.gov.br/resolucoes-do-conarq/335-resolucao-n-43-de-04-desetembro-de-2015.html. Acesso em: 16 abr. 2019.

BRASIL. Decreto no 8936, de 19 de dezembro de 2016. Institui a Plataforma de Cidadania Digital e dispõe sobre a oferta dos serviços públicos digitais, no âmbito dos órgãos e das entidades da administração pública federal direta, autárquica e fundacional. Brasília, DF: Diário Oficial da União, 2016. Disponível em: http://www.planalto.gov.br/ccivil_03/_Ato2015-2018/2016/Decreto/D8936.htm. Acesso em: 16 abr. 2019.

BRASIL. Portaria n ${ }^{\circ} 1.106 / P R E S / I N S S$, de 30 de junho de 2017. Dispõem sobre procedimentos para expansão do Projeto INSS Digital - Uma nova forma de atender. Brasília, DF: Publicada no BS 124, de 30 de junho de 2017.

BRASIL. Lei $\mathbf{n}^{\circ}$ 13874, de 20 de setembro de 2019. Institui a Declaração de Direitos de Liberdade Econômica; estabelece garantias de livre mercado; e dá outras providências. Lei No 13.874, de 20 de Setembro de 2019: Conversão da Medida Provisória nº 881, de 2019. 1. ed. Brasília, DF, 20 set. 2019. Disponível em: http://www.planalto.gov.br/ccivil_03/_Ato2019-2022/2019/Lei/L13874.htm. Acesso em: 22 set. 2019. 


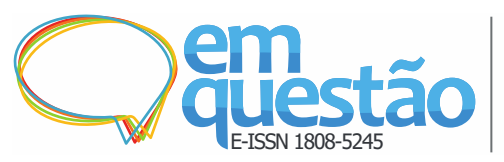

Diagnóstico do processo de implantação do INSS Digital: perspectivas e gestão da informação

Patrícia Soares Silva Bertotti, Ana Clara Cândido, Luciane Paula Vital

CERVO, A.L.; BERVIAN, P.A.; SILVA, R. Metodologia científica. 6. ed. São Paulo: Person Prentice Hall, 2007.

CHOO, C. W. A organização do conhecimento: como as organizações usam a informação para criar significado, construir conhecimento e tomar decisões. São Paulo: Senac, 2003. 425 p.

CONSELHO NACIONAL DE ARQUIVOS (Brasil). Câmara Técnica de Documentos Eletrônicos. e-ARQ Brasil: Modelo de Requisitos para Sistemas Informatizados de Gestão Arquivística de Documentos. Rio de Janeiro: Arquivo Nacional, 2011. 136 p. Disponível em: http://www.siga.arquivonacional.gov.br/images/publicacoes/e-arq.pdf. Acesso em: 13 de mai. 2020.

DAVENPORT, T. H. Ecologia da informação: porque só a tecnologia não basta para o sucesso na era da informação. São Paulo: Futura, 1998.

DAVENPORT, T. H.; PRUSAK, L. Conhecimento empresarial: como as organizações gerenciam o seu capital intelectual. 15. ed. Rio de Janeiro: Elsevier, 2003.

DURANTI, L. Registros documentais contemporâneos como prova de ação. Trad. Adelina Novaes e Cruz. Estudos históricos, Rio de Janeiro, v.7, n13, p.49-64, jan./jun. 1994.

FLORES, D. Cadeia de custódia dos documentos arquivísticos digitais: do SIGAD ao RDC-Arq. Palestra. UFES. Vitória - ES. 76 slides, color, Padrão Slides Google Drive/Docs 4x3. Material elaborado para a Palestra no Curso de Arquivologia, 16 de junho de 2016. Disponível em: http://www.arquivologia.ufes.br/sites/arquivologia.ufes.br/files/field/anexo/cadeia_de_cu stodia_dos_documentos_arquivisticos_digitais-_do_sigad_ao_rdc-arq.pdf. Acesso em: 08 de jun. 2019.

INDOLFO, A. C. Avaliação de documentos de arquivo: atividade estratégica para a gestão de documentos. Revista do Arquivo Geral da Cidade do Rio de Janeiro, Rio de Janeiro, v. 6, p. 13-37, anual, 2012. Disponível em:

http://www0.rio.rj.gov.br/arquivo/pdf/revista_agcrj_pdf/revista_AGCRJ_6_2012.pdf

INNARELLI, H. C. Preservação digital: a gestão e a preservação do conhecimento explícito digital em instituições arquivísticas. InCID: Revista de Ciência da Informação e Documentação, Ribeirão Preto, v. 3 n. 2, n. 2, p. 48-63, jul./dez. 2012.

DOI: 10.11606/issn.2178-2075.v3i2p48-63 Acesso em: 31 mar. 2019.

LE COADIC, Y.F. A ciência da informação. 2. ed. Brasília, DF: Briquet de Lemos, 2004. 
LEHMKUHL, C. S.; MACEDO, D. D. J.; SILVA, E. C. L. Uma análise qualitativa dos repositórios digitais arquivísticos confiáveis (rdc-arq). Encontro Nacional de Pesquisa em Ciência da Informação, n. XIX ENANCIB, 2018. Disponível em:

http://hdl.handle.net/20.500.11959/brapci/102547. Acesso em: 13 maio 2020.

MENDONÇA, F. M.; ZAIDAN, F. H. Ontologias para organização da informação em processos de transformação digital. Em Questão, v. 25, n. 1, p. 295-320, jan./abr.2019. DOI: 10.19132/1808-5245251.295-320. Acesso em: 23 abr. 2019.

PAES, M. L. Arquivo: teoria e prática. 3. ed. Rio de Janeiro: FGV, 2004, 228 p.

ROUSSEAU, J. Y.; COUTURE, C. Fundamentos da disciplina arquivística. Tradução de Magda Bigotte de Figueiredo. Portugal: Lisboa, Dom Quixote, 1998.

SANTOS, H. M.; FLORES, D. Repositórios digitais confiáveis para documentos arquivísticos: ponderações sobre a preservação em longo prazo. Perspectivas em Ciência da Informação, Belo Horizonte, v. 20, n. 2, p. 198-218, abr./jun.2015. Disponível em: http://hdl.handle.net/20.500.11959/brapci/36891. Acesso em: 31 mar. 2019.

TOLBOOM, I. The impact of digital transformation: A survey-based research to explore the effects of digital transformation on organizations. Amsterdam: Master Thesis Report, 2016.101 p. Disponível em: https://repository.tudelft.nl/islandora/object/uuid:d1d6f874-abc1-4977-8d4e4b98d3db8265/datastream/OBJ. Acesso em: 12 maio de 2019.

YIN, R. K. Estudo de caso: planejamento e método. 3. ed. Porto Alegre: Bookman, 2001.

\title{
A diagnosis of the implementation of INSS Digital: information management perspectives
}

\begin{abstract}
In the executive branch of the Brazilian federal government, a huge amount of documents is processed, and document management must not only store the documents, but also preserve them and ensure long-term access to them. This work seeks to highlight, through a survey of the current state of the Brazilian National Social Security Institute (INSS)'s digital transformation process, the challenge of producing and preserving
\end{abstract}


reliable, authentic and accessible digital documents. This study aims to identify and point out the perspectives of information management in the digital transformation process at the INSS by means of a diagnostic analysis. It is a qualitative, exploratory and descriptive case study. The results obtained express the need for such institution to adopt a management policy that covers all aspects of digital preservation, from to final destination.

Keywords: Archivology. Information management. Digital preservation. Digital document.

Recebido: 25/03/2020

Aceito: $22 / 05 / 2020$

\section{Declaração de autoria:}

Concepção e elaboração do estudo: Patricia Soares da Silva Bertotti, Ana Clara Cândido, Luciane Paula Vital.

Coleta de dados: Patricia Soares da Silva Bertotti.

Análise e discussão de dados: Patricia Soares da Silva Bertotti, Ana Clara Cândido, Luciane Paula Vital.

Redação: Patricia Soares da Silva Bertotti.

\section{Como citar:}

BERTOTTI, Patrícia Soares Silva; CÂNDIDO, Ana Clara; VITAL, Luciane Paula. Diagnóstico do processo de implantação do INSS Digital: perspectivas e gestão da informação. Em Questão, Porto Alegre, v. 27, n. 1, p. 456-483, jan/abr. 2021 . Doi: http://dx.doi.org/10.19132/1808-5245271.456-483

\footnotetext{
i Gerenciador Eletrônico de Tarefas (GET).
} 